\title{
JUURNAL.RU
}

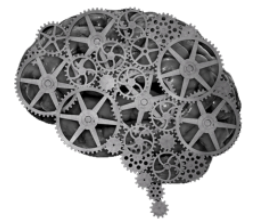

COMPANY GROUP "INTELLEKT"

\author{
Мартынова С.Б. \\ НИУ «БелГУ» \\ г. Белгород, Россия
}

doi: 10.18411/lj2016-5-3-13

\section{Аппроксимация в газетном дискурсе}

Аннотация: В данной статье излагаются результаты анализа частотности использования и распределения аппроксиматоров в двух жанрах англоязычных газетных статей: передовой и новостной. Выбор направления исследования обусловлен несколькими причинами: во-первых, в большинстве статей и исследований аппроксимация рассматривалась в основном в учебном или научном дискурсе. Во-вторых, газеты несут чрезвычайно разнообразную по своему характеру информацию. Для ее передачи используются языковые средства, в том числе и аппроксимативные, которые имеют определенные семантические и прагматические особенности, учитываемые авторами статей для достижения конкретных целей. Полученные выводы сделаны на основе контекстуального анализа около 9000 употреблений аппроксиматоров в 15 статьях (передовых статьях и новостных репортажах примерно одинакового объема) из 4 разных источников. Установлено, что в передовицах средства аппроксимации используются чаще для смягчения высказывания, чем в других газетных жанрах; аппроксиматоры, функционирующие в передовых статьях газетного дискурса, отличаются большим разнообразием и семантически, и прагматически.

Ключевые слова: распределение, аппроксиматоры, частота, передовая статья, новостной репортаж, аппроксимащия. 
В последнее время исследователей все чаще интересует проблема аппроксимации в текстах научного стиля. Аргументы в пользу такого рода исследований вполне обоснованы: английский язык стал лингва-франка научного дискурса. Ученым, независимо от их национальности, приходится изъясняться на этом языке, если они хотят быть членами международного научного сообщества. Поэтому аппроксимации, наряду с другими языковыми и культурными, а также риторическими аспектами речи, стали уделять большее внимание, исследуя ее в кросс-культурном и кросс-дисциплинарном научном дискурсе. Однако аппроксимативные стратегии используются и в текстах жанров других стилей речи. Уже в повседневной речи достаточно средств для того, чтобы передавать информацию неточно, приблизительно, не говоря уже об институциональных отношениях, которые охватывают различные уровни общения людей: от организаций - как высшего уровня социального структурирования - до конкретного уровня, такого, например, как определенное событие или действие. Участники коммуникации прибегают к применению средств аппроксимации по разным причинам: как правило, чтобы не оскорбить адресата, сохранить свою позицию, не передать неправдоподобную или непроверенную информацию, чтобы признать различия во влиятельности, степени социальной дистанции и т. д.

Данное исследование направлено на изучение средств аппроксимации в двух жанрах газетного дискурса на английском языке: передовой статье и новостном репортаже и призвано дать ответ на следующие вопросы: а) какова частотность аппроксиматоров в передовой статье и новостном репортаже? и б) используют эти газетные жанры аналогичные или различные средства аппроксимации?

В газетах публикуется материал чрезвычайно разнообразного характера: новостные сюжеты, сообщения, реклама и объявления, передовые статьи, головоломки, кроссворды и тому подобное. Текст газетного стиля - это особый вид дискурса со своими структурными особенностями, словами и фразами. По 
мнению И.Р. Гальперина, «...газетный стиль может быть определен как система взаимосвязанных лексических, грамматических и фразеологических средств, которая рассматривается обществом как отдельное лексическое единство, которое служит цели информирования и инструктирования читателя» [1, с. 97]. Однако, в этом «языковом единстве» вышеуказанные средства распределяются по-разному, в зависимости от жанра газетной статьи. Следовательно, можно предположить, что каждый газетный жанр, преследуя разные интересы и цели, использует аппроксиматоры тоже по-разному. Мы проанализировали реализацию категории приблизительности на примере англоязычных передовых статей и новостных репортажей, так как они представляют собой разные жанры газетного дискурса и выполняют различные функции. Главная функция новостных репортажей - объективно информировать читателя, представлять ему неопровержимые факты, а передовицы направлены на формирование мнения, влияние, иногда даже на манипуляцию общественным мнением. Поэтому авторы передовиц и репортеры прибегают к различным наборам синтаксических структур, лексики, стилистических приемов и т. д. В данной статье рассматриваются частотность и разнообразие средств аппроксимации в передовых статьях и новостных репортажах. Исследование базируется на подробном контекстуальном анализе 9000 аппроксиматоров из 15 передовых статей и новостных репортажей примерно одинакового объема из 4 разных интернет-газет: The Mirror, The Telegraph, The International New York Times и The Independent. Сплошная выборка примеров, в которых функционирует то или иное средство аппроксимации, позволила не только провести количественный анализ с целью определения частотности применения и распределения аппроксиматоров в передовице и новостном репортаже, но и установить основные прагматические нюансы аппроксимации.

Лингвисты почти единодушны во мнении, что аппроксимация носит прагматический характер, является одним из способов смягчения тона высказываний, который в противном случае может показаться слишком резким 
и категоричным, способом выражения вежливости или уважения к незнакомым людям, начальству и т.д. Дж. Лакофф, будучи пионером в этой области, утверждает, что аппроксимация появляется, если элемент ситуации не имеет четкого количественного выражения и необходимо приблизительно представить его в речи [4]. В ходе дальнейших исследований категории аппроксимации было выявлено, что аппроксиматоры, применяемые в повседневной и институциональной коммуникации, имеют определенные общие черты, хотя мнения ученых расходятся относительно средств аппроксимации, их функций, причин ее использования и т.д. Так, например, Р. Марканен и Х. Шрёдер различают два типа аппроксимации (точнее, две причины для ее использования): первый тип имеет дело с определенными языковыми элементами, которые влияют на условия истинности высказывания; второй - отражает степень уверенности говорящего в истинности значения целого предложения [5].

В обобщенном виде причины аппроксимации и различные функции аппроксиматоров представлены в работе К. Хайланда. Ученый разделил аппроксиматоры в контексте научного дискурса на содержательноориентированные и читатель-ориентированные. Первый тип, в свою очередь, делится на точность-ориентированные и писатель-ориентированные. Классификация аппроксиматоров К. Хайланда предполагает также, что аппроксимативные стратегии используются главным образом по двум причинам: чтобы сосредоточиться на точности высказываний и для «самозащиты» писателя [3].

Анализ работ по проблемам аппроксимации свидетельствует о том, что не только аппроксимация трактуется неоднозначно, но и аппроксиматоры представляют собой довольно противоречивую картину: как классификация, так и сам набор аппроксиматоров варьируют в работах разных авторов, поскольку нет четких унифицированных критериев их выделения. Согласно Р. Марканену и Х. Шрёдеру, невозможно сократить перечень средств выражения категории аппроксимации, потому что никакие языковые элементы не являются 
по своей природе приблизительными, однако они могут приобрести это качество в контексте [5]. Другими словами, лингвисты отмечают, что реализовать семантические оттенки приблизительности в контексте могут многие слова и выражения английского языка: модальные глаголы (напр. may, might, could), модальные наречия (possibly, perhaps, probably), существительные с модальным значением (например, possibility), глаголы с семантикой сомнения (например, suggest, assume и т.д.), аппроксиматоры степени, количества, частоты и времени (например, roughly, sort of, quite и т. д.), дополнительные придаточные предложения (например, it could be the case that..., it appears that... и т. д.), придаточные предложения условия (напр. if true, if anything и т. д.). А Дж. Холмс относит к аппроксиматорам также колебания голоса и такие обороты, как уои know, I think, sort of, которые она называет прагматическими частицами. По мнению автора, разделительные вопросы также функционируют в качестве аппроксиматоров.

Различные средства аппроксимации и их многофункциональность иногда приводят к затруднениям при исследовании и интерпретации этой категории. Мы не ставим перед собой задачу дать четкий перечень аппроксиматоров, которые встречаются в англоязычном газетном дискурсе. C учетом представленных выше типов средств аппроксимации мы попытались выявить частотность применения аппроксимативных средств в газетных текстах разных жанров и их прагматическую значимость.

Полученные результаты показывают, что на тысячу слов газетного дискурса в передовых статьях частотность использования аппроксиматоров выше, чем в новостных репортажах (см. таблицу 1): 
Табл. 1.

Общая частота использования аппроксиматоров на тысячу слов

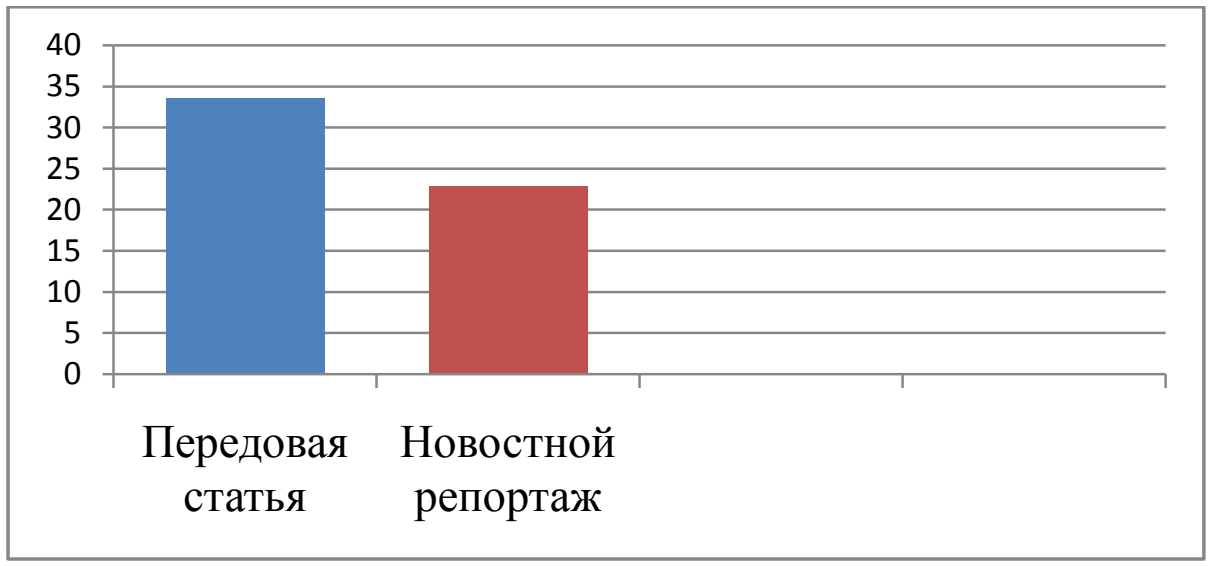

Передовая статья характеризуется довольно субъективным и в то же время навязчивым стилем изложения материала. Главный редактор либо группа известных обозревателей комментируют, выражают свое мнение по актуальным вопросам, представляющим общий интерес и имеющим большое значение, участвуют в политических или этических дискуссиях. Они критикуют, хвалят или осуждают определенные события. В отличие от передовой статьи новостной репортаж, как правило, преподносит факты или события объективно. Мы полагаем, что различные функции и задачи двух газетных жанров влияют, среди прочего, на плотность распределения аппроксиматоров. Автор передовицы, критикуя, восхваляя или осуждая кого-то или что-то, вынужден в большей степени опираться на некоторые смягчающие языковые средства, например, такие как контент-ориентированные и читатель-ориентированные аппроксиматоры. По мнению К. Хайланда, контент-ориентированные аппроксиматоры предназначены для того, чтобы смягчить взаимоотношение между содержанием высказывания и представлением о реальности, они как бы «приближают» друг к другу мнения о том, что писатель говорит о мире, и о том, что сам мир думает о себе [3]. Эти аппроксиматоры подразделяются на точность-ориентированные, которые сконцентрированы на содержании предложения (1), и писатель-ориентированные, основная задача которых оградить писателя от негативной реакции на высказывание, ограничить личную 
ответственность за истинность (2):

(1) They lost just one of their opening 12 games and all seemed well going into the New Year, but then came a wobble in January and the 110m signing of Jordan Rhodes (it is said Karanka wanted Fulham's Ross McCormack instead).

(2) Perhaps these basics of media relations ought not to matter, but they do and Mr Corbyn is no good at them.

В пр. 1 аппроксиматор is said подразумевает, что утверждение основано не на реальных знаниях; а в пр. 2 автор передовицы старается избежать явной ответственности за свои утверждения, используя для этого аппроксиматор. Согласно К. Хайланду, чем больше автор обобщает и интерпретирует, тем чаще использует аппроксимацию; таким образом, уже изначально передовая статья аппроксимируется [3]. Хотя зарубежные исследователи не проводили статистического анализа данных о соотношении точность-ориентированных и писатель-ориентированных аппроксиматоров в передовых статьях и новостных репортажах, наши наблюдения над фактическим языковым материалом позволяют установить определенную закономерность: последний тип аппроксиматоров более характерен для передовиц, в то время как точностьориентированные средства являются общими для обоих видов статей.

Анализ источников, в каждом из которых встречались одинаковые типы аппроксиматоров, представлен в таблице 2 .

Как видим, только в одном источнике, The New York Times, в новостных репортажах количество аппроксиматоров больше, чем в передовых статьях. Отметим, что исследование плотности использования аппроксиматоров в отдельных источниках не было целью данной статьи; это было сделано для того, чтобы дополнить общее представление о распределении средств аппроксимации в текстах двух газетных жанров. Тем не менее, можно сделать некоторые обобщения. Газетный стиль - один из стилей, который претерпевает колоссальные изменения и использует не только средства для изложения объективной, фактуальной информации, но и субъективной. Некоторые бывшие 
влиятельные издания, например, The Independent и The Daily Telegraph, стали малоформатными газетами; следовательно, их стиль претерпел значительные изменения, одним из которых является то, что даже в новостных репортажах наметилась тенденция к аппроксимации. Конечно, The New York Times не принадлежит к этой группе газет, чем и можно объяснить такие различия. Но чтобы доказать правильность наметившейся тенденции, необходим больший корпус контекстов с аппроксиматорами.

Табл. 2. Частота использования аппроксиматоров на тысячу слов газетного дискурса в разныхх источниках

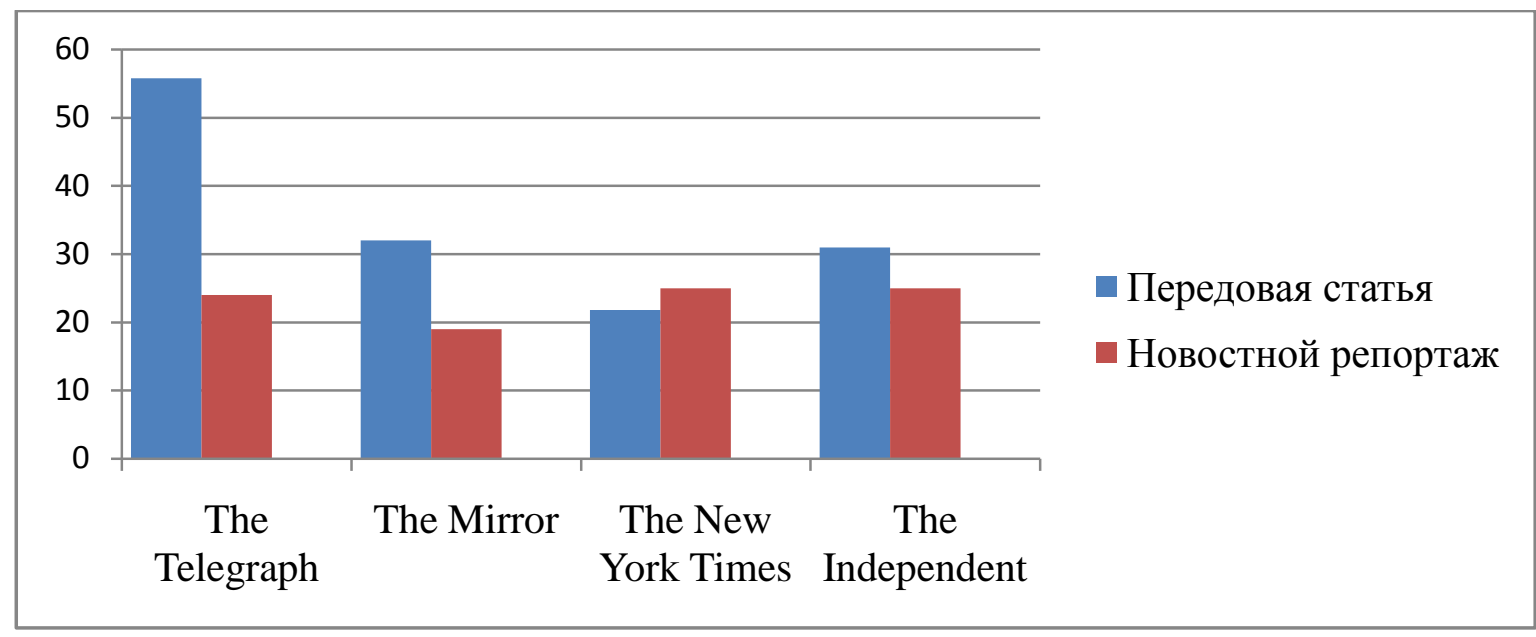

Исследование контекстов с аппроксиматорами наглядно доказывает, что каждый газетный жанр предполагает доминирование определенных средств аппроксимации. К наиболее частотным средствам аппроксимации в передовице относятся глаголы will (в его эпистемической модальности) (10), should (9), придаточные предложения условия (8), глагольные лексемы would (8), may (6), can (4), seem (4), appears (4), could (3), might (3). В то же время наиболее предпочтительными и часто применяемыми аппроксиматорами в новостном репортаже являются глагольные формы is/was said (11), would (7), can (5), could (5), expect/is expected (4), may (3), might (2), appears (2), are thought (2), were found (2). Самым разительным отличием аппроксимированных высказываний в 
передовой статье и новостном сообщении является то, что новостные репортажи содержат больше пассивных конструкций. Рассмотрим некоторые примеры:

(3) The as-yet untitled Star Wars spin-off project will centre around Han Solo. It is currently thought to be in pre-production and the first photo from the set was posted on Thursday by co-director Christopher Miller.

(4) Located just outside Damascus, Sednaya holds 4,000 political prisoners, and is said to be a hotbed of torture and political killings.

Очевиден тот факт, что журналисты не берут на себя ответственность за то, что они заявляют, они хотят быть объективными, а контент-ориентированные аппроксиматоры - пассивные конструкции - служат этой цели.

Наоборот, в передовицах преобладают модальные глаголы и придаточные предложения условия, выполняющие функцию аппроксимации:

(6) He claimed at least twice that he could win even if the party did not come together.

(7) It has been known for some time that the British penal system is crumbling, but no picture could be bleaker than that painted by new figures exposing the extent of failure inside our prison system.

В пр. 6 аппроксиматор ориентирован на содержание, так как он выражает некий скептицизм по поводу высказывания; автор не уверен насчет притязаний лица, о котором идет речь, и принимает их с определенной осторожностью. В пр. 7 применяется писатель-ориентированный аппроксиматор, так как он снижает степень ответственности автора за выражаемую оценку, присутствие автора в тексте отодвигается на задний план.

Кроме того, следует отметить, что в обоих газетных жанрах довольно часто прибегают к двойной, тройной или множественной аппроксимации высказывания.

(8) Yet that may not be enough for it seems clear that many athletes have become disillusioned by British Cycling's organisational culture more broadly.

В заключение необходимо подчеркнуть следующее. Аппроксимация как 
прагматическая категория, основной задачей которой является смягчение категоричности высказывания и уклонение от ответственности за истинность сообщаемого или, наоборот, стремление к точности информации, отсутствие в языковой системе более точного обозначения, широко используется в различных жанрах газетного дискурса. В большинстве случаев частотность использования аппроксиматоров в передовой статье выше, чем в новостном репортаже. В англоязычных изданиях с малым тиражом наметилась тенденция к росту аппроксимированных высказываний и в новостных репортажах. Так как передовая статья и новостной репортаж как два жанра газетного стиля выполняют разные функции: убеждать и информировать читателя, то они используют различные языковые средства для достижения этих целей, в том числе и средства аппроксимации. Исследование показало, что авторы передовиц в большей степени склонны подстраховываться, смягчать категоричность высказываний, чем новостные корреспонденты. В передовых статьях и новостных репортажах наблюдаются также различия относительно средств аппроксимации для выполнения соответствующих функций.

\section{Литература}

1. Гальперин И.Р. Очерки по стилистике английского языка. - М., 1968.

2. Holmes J. Women, Men and Politeness. - Longman Group UK Limited, 1999.

3. Hyland K. Hedges, Boosters and Lexical Invisibility: Noticing Modifiers in Academic Texts. - In: Language Awareness. Vol. 9, No 4, 2000.

4. Lakoff G. Hedges: A Study in Meaning Criteria and the Logic of Fuzzy Concepts. - In: Chicago Linguistic Society Papers, 1972.

5. Markkanen, R. \& Schröder, H. Hedging: a Challenge for Pragmatics and Discourse Analysis. - Berlin: de Gruyter, 1997. P. 3-18. 